\title{
A Tribute to the Memory of Dr. Tatsuo Kokubu
}

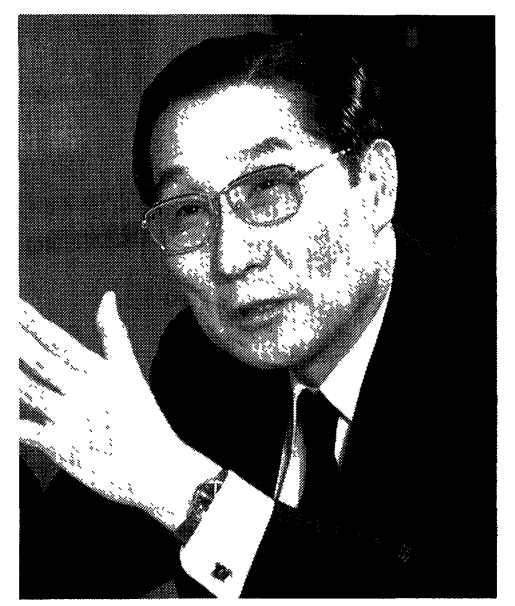

On July 12, 1995 Dr. Tatsuo Kokubu, Director of Kinki Central Hospital, and Professor Emeritus, Ehime University, succumbed at the age of 69 years to intraperitoneal metastasis of gastric cancer. Only 7 months had passed since surgery in November of last year. Dr. Kokubu also did not expect such a rapid progression of his disease; the remaining members of the Japanese Society of Hypertension deeply regret that he did not have adequate time to express all his valuable thoughts for the development of the Society and diversification of its future roles.

Dr. Kokubu graduated from Osaka University Medical School in March 1951. After serving as an intern at Osaka University Hospital for a year, he passed the National Examination for Medical Practitioners. In the same year, he entered the Third Department of Internal Medicine, Osaka University Medical School, and became involved in research on atherosclerosis under the former graduate-school research scholarship system. While a graduate student, he published a research paper, entitled "Production of Coronary Heart Disease in the Rabbit by Lanolin Feeding," in Circulation Research (5: 645-649, 1957). As a result of this study, he received a degree of Doctor of Medicine in 1958. This valuable report was the first to describe the production of a model of myocardial infarction in the rabbit. The study, which would have attracted considerable attention had it been published 20 years later, was unfortunately not acknowledged adequately by societies in Japan at the time of publication. In the United States, Dr. Kokubu's research was considered a significant contribution to cardiovascular research, and from January 1960 Dr. Kokubu studied for 1 year and 9 months under Dr. Pollak at Dover Medical Research Center in the United States. He studied tissue cultures of smooth muscle cells of the rabbit aorta, and his work on atherosclerosis using tissue cultures of vascular smooth muscle cells was at the forefront of research in that era. Shortly after Dr. Kokubu returned to Japan, the late Dr. Yuichi Yamamura was appointed Professor of the Third Department of Internal Medicine, Osaka University Medical School. Consequently, the research focus of Dr. Kokubu shifted from atherosclerosis to hypertension, with particular emphasis on biochemical research of the renin-angiotensin system. Dr. Kokubu's first research project under Prof. Yamamura involved angiotensinase. The primary material for this project was a small amount of Hypertensin CIBA (angiotensin II) handed to him by Prof. Yamamura. At the same time, Dr. Kokubu started to study renin inhibitors. The first report derived from this research, entitled "Peptide Inhibitors of the Renin-Angiotensin System," was published in Nature (217: 456-457, 1968). In 1965 Dr. Kokubu was appointed Lecturer, Osaka University, and in 1971 he became Associate Professor. In 1973 the School of Medicine was established at Ehime University, and in April 1974 Dr. Kokubu was appointed Professor, the Second Department of Internal Medicine. 
After moving to Ehime University, Dr. Kokubu continued his research on renin inhibitors and made several presentations at the annual fall conference and scientific sessions held by the Hypertension Council of the American Heart Association. These papers were also published in Hypertension, Journal of Hypertension, and other leading international journals. In 1988, when the 12th Scientific Meeting of the International Society of Hypertension was held in Japan, Dr. Kokubu served as co-chairman with Prof. Hans R. Brunner from Switzerland at the official satellite symposium "Renin Inhibitors-Present and Future." Dr. Kokubu has to his credit over 78 original reports written in English on the basic and clinical research of the renin-angiotensin system, including studies on renin inhibitors, angiotensin converting enzyme, angiotensinogen, and angiotensinases. Including these articles, Dr. Kokubu has written over 200 articles, case reports, and overviews in English. After being appointed Professor, Ehime University, Dr. Kokubu was extremely active internationally and represented Japan as a member of the International Society of Hypertension and a fellow of the American Heart Association's Council for High Blood Pressure Research.

In March 1988, Dr. Kokubu resigned from his position as Professor, Ehime University School of Medicine, before reaching the official retirement age and became Director, Kinki Central Hospital. In 1989 he was granted the title of Professor Emeritus, Ehime University. While Director, Kinki Central Hospital, he established the Hypertension Center at the Hospital in 1991, and as Director of the Center initiated clinical research on hypertension.

When the Japanese Society of Hypertension was established in April 1978, he was one of the founders; he also served as a Trustee for many years. He contributed substantially to the Society's development. From April 1983, Dr. Kokubu served as Chairman, Japanese Society of Hypertension for one year, and he organized the 6th General Meeting of the Society in September 1983. In 1993 he was made an honorary member of the Japanese Society of Hypertension. From 1992 the Japanese Society of Hypertension started to publish the English language journal "Hypertension Research-Clinical and Experimental-," which replaced the Society's Japanese journal "Hypertension." As the journal's first Editor-inChief, Dr. Kokubu actively promoted international awareness of the journal. Personally, he was instrumental in designing the journal cover (based on the mosaic theory of Dr. Page), inviting many internationally authorities on hypertension to serve as reviewers, requesting leading researchers to write overview reports for the first article of each issue, and in striving to have the Journal included in Current Contents and other international media. The Journal is now published quarterly, but Dr. Kokubu wanted to make it a bimonthly publication as soon as possible, a conviction held until his death. We would like to express our sincere admiration for Dr. Kokubu's many achievements and express our appreciation for the significant contributions he has made to the Japanese Society of Hypertension.

On behalf of all members of the Japanese Society of Hypertension, I pray for the repose of his soul. 